\title{
The Effects of Curcumin on Alpha Amylase in Diabetics Rats
}

\author{
Mahmood Najafian ${ }^{1,{ }^{*}}$ \\ ${ }^{1}$ Department of Biology, Jahrom Branch, Islamic Azad University, Jahrom, IR Iran \\ "Corresponding author: Mahmood Najafian, Department of Biology, Jahrom Branch, Islamic Azad University, Jahrom, IR Iran. E-mail: m.najafian@jia.ac.ir
}

Received 2014 July 12; Accepted 2014 October 4.

\begin{abstract}
Background: One of the therapeutic approaches to lower postprandial blood glucose is to inhibition breakdown of starch by inhibiting carbohydrate hydrolysis enzymes. Alpha-amylase catalyzes the hydrolysis of $\alpha$-(1,4)-D-glycosidic linkages of starch and other glucose polymers. Inhibitors of this enzyme could be used in the treatment of diabetes.

Objectives: Based on this purpose we examined the effect of curcumin on alpha amylase and its IC50 and Ki.

Materials and Methods: In this experimental study, 60 rats were divided into two major groups, normal and diabetic, and each was subsequently divided into five subgroups. One of them as control group that received grape seed oil and four of them as experimental groups that received curcumin at $10,20,40$ and $80 \mathrm{mg} / \mathrm{kg}$ (each group include six rats). Blood glucose levels were measured every three days. Serum insulin levels were measured three times, in the first day, middle and end of the experimental period. The activity of serum alpha amylase was measured in the end of experimental period.

Results: The results showed that curcumin is a competitive inhibitor for alpha amylase with IC50 $=51.32 \mu \mathrm{M}$ and $\mathrm{Ki}=20.17 \mu \mathrm{M}$. In both diabetic and normal groups in all doses nearly dose dependent manner reduced blood glucose and insulin levels. In both diabetic and normal groups decreased levels of serum alpha amylase activity.

Conclusions: It may be concluded that curcumin is a potent inhibitor of alpha amylase and has beneficial effects in the treatment of overweight and diabetes
\end{abstract}

Keywords: Curcumin, Alpha Amylase, Diabetes, Hyperglycemia

\section{Background}

Diabetes mellitus is a major cause of morbidity and mortality and its global prevalence is growing rapidly $[1,2]$. It is a serious endocrine syndrome with poor metabolic control and responsible for increased risk of diseases such as atherosclerosis, renal failure, blindness or diabetic cataract [3-5]. Diabetes mellitus is one of the most common endocrine disorders and is characterized by hyperglycemia, hypercholesterolemia and hypertriglyceridemia, resulting from defects in insulin secretion or reduced sensitivity of the tissue to insulin (insulin resistance) and/or combination of both [6, 7]. Different types of oral antidiabetic agents such as biguanides and sulphonylurea are available along with insulin for the treatment of diabetes mellitus, but have side effects associated with their uses [8]. A large number of studies are in progress to identify natural substances that are effective in reducing the severity of diabetes. Ayurveda is a science that uses herbal medicines. From ancient times, some of these herbal preparations have been used in the treatment of diabetes. Even the world health organization (WHO) approves the use of plant drugs for different diseases, including diabetes mellitus $[9,10]$. One of these plant drugs is curcumin. Curcumin is a natural polyphenol derived from the plant Curcuma longa, commonly called turmeric. The curcuminoids are natural phenols and are responsible for the yellow color of turmeric [11-13]. Curcumin has been shown to have a wide spectrum of biological actions. These include its anti-inflammatory, antioxidant, anticarcinogenic, antimutagenic, anticoagulant, antifertility, antidiabetic, antibacterial, antifungal, antiprotozoal, antiviral, antivenom, antiulcer, antialzheimer and hypocholesteremic activities [14-16]. The most important methods for treatment of diabetes are inhibition of digestion and absorption of carbohydrates in small intestine. That is occurring in two manners. The first is inhibition digestion of carbohydrates with inhibition of alpha amylase, the enzyme that decomposed of carbohydrates and the second is inhibition of absorption via sodium/glucose co-transporters (SGLT1 and SGLT2), the sugar transporter systems $[17,18]$. Flavonoid-rich fractions of plants have also been reported to be effective as antihyperglycemic and antihyperlipidemic agents in animal models of diabetes [19]. Plants derived polyphenols such as quercetagetin, fisetin and quercetin, which belong to the flavonoid family have been shown to be effective inhibitors of mammalian alphaamylase with IC50s in the order of micromolar [20].

Copyright ( ) 2015, Zahedan University of Medical Sciences. This is an open-access article distributed under the terms of the Creative Commons Attribution-NonCommercial 4.0 International License (http://creativecommons.org/licenses/by-nc/4.0/) which permits copy and redistribute the material just in noncommercial usages, provided the original work is properly cited. 


\section{Objectives}

Since curcumin [1, 7-bis (4-hydroxy-3-methoxyphenyl)1, 6-heptadiene-3,5-dione] could be viewed as a flavonoid of polyphenolic compounds, in this investigation we researched the inhibitory effect of curcumin on alpha amylase and the effect of curcumin orally on blood glucose levels in STZ-induced diabetic and normal rats.

\section{Materials and Methods}

\subsection{Chemicals}

In this experimental study, human pancreatic amylase (HPA), curcumin, dialysis membrane, 3, 5-dinitrosalisylate reagent (DNS) and sodium potassium tartrate were from Sigma chemicals company (St Louis, MO, USA). Streptozotocin was from Pharmacia and Upjohn (Kalamazoo, MI, USA). Dimethyl sulfoxide, soluble starch, maltose and other chemicals were obtained from Merck chemicals company (Darmstadt, Germany).

\subsection{Determination Activity of Amylase}

Bernfeld method [21] was used for the enzyme assay. Curcumin was dissolved in dimethyl sulfoxide (DMSO) and used as inhibitor of alpha amylase. Starch was dissolved in a phosphate buffer $\mathrm{pH}=7$ (w/v: $0.5 \%, 1.0 \%, 2.0 \%, 2.5 \%)$ and used as substrate of alpha amylase. The enzyme was previously incubated for 30 minutes in the presence of various concentrations $(0,25,50$ and $75 \mu \mathrm{M})$ of curcumin (as sample test) and DMSO (as control). Then added starch solution and incubated in room temperature for 3 minutes. After this time, the reaction was stopped by the addition of 3, 5-dinitrosalicylic acid (DNS) reagents. Samples were then placed in a boiling water bath for 5 minutes and subsequently cooled down to room temperature, then added $5 \mathrm{~mL}$ distilled water and was mixed. Absorbance was measured at $540 \mathrm{~nm}$ against a blank prepared using the identical method, except the enzyme solution was added to the mixture after the addition of the DNS solution. The optical density (OD) values were then converted to micromole of maltose equivalent using a standard curve obtained from the known concentration of maltose prepared with the same buffer solutions $(Y=0.0001 \mathrm{X}+0.0025)$. A unit of enzyme activity was defined as the amount of enzyme that released $1 \mu \mathrm{mol}$ of maltose per minute under the assay conditions specified. Remaining activity was calculated as a percentage by comparison with the control sample activity, the activity of enzyme in presence of DMSO. All experiments were done at least three times and average values reported $[21,22]$.

\subsection{Dialysis Enzyme-Inhibitor}

Reversibility of inhibition was checked with the technique of dialysis tube. Enzyme-curcumin was dialised in dialysis tube in $0^{\circ} \mathrm{C}$ for 24 hours. Enzyme activity in the presence of curcumin and comparing this value with the one obtained after extensive dialysis of the enzymecurcumin solution, show that nearly all curcumin go out of dialysis tube. This means that the attachment of curcumin to enzyme is reversible.

\subsection{Animals}

Sixty male adult Wistar rats (2.5 months) weighting 190 $\pm 15 \mathrm{~g}$ were used in these experiments. The animals were housed as 6 rats per cage at room temperature $\left(22-24^{\circ} \mathrm{C}\right)$. During daylight hours (8:00 to 20:00) room lights were turned on. They were fed with standard rodent diet. Food and water were ad libitum.

\subsection{Diabetes Induction}

Streptozotocin-induced hyperglycemia has been described as a useful experimental model to study the activity of antidiabetic agents. Streptozotocin (STZ) selectively destroyed the pancreatic insulin secreting $\beta$ cells [8]. It was allowed to acclimatize the animals 3 days before experiment in new environment. For two days prior to the experiment, diabetic state was induced by a single i.p. injection of streptozotocin $(70 \mathrm{mg} / \mathrm{kg}$, dissolved in a citrate buffer 0.1 $\mathrm{M}, \mathrm{pH}=4.5$ ), and the blood glucose levels were measured after 2 days, then was started the experiment period [18].

\subsection{Treatment With Curcumin}

Curcumin, being virtually insoluble in aqueous medium. It was necessary to choose a suitable hydrophobic solvent for its administration to rats, hence the choice of grape seed oil. Grape seed ethanolic extract has been suggested to be beneficial in a rat model of type 2 diabetes. The main component of grape seed "oil" seems to be linoleic acid [20]. Different doses of curcumin and grape seed oil (as solvent of curcumin) were administrated orally for 30 days through a gastric cannula in a single dose $(0.5 \mathrm{~mL})$ at $8: 30 \mathrm{am}$. Rats randomly were divided into two major groups: normal rats (N), diabetic rats (D), each was subsequently divided into five subgroups (each group included 6 rats), as defined below: I) normal control group (NO): rats in this group received grape seed oil (O); II) normal experimental groups: rats in these groups received curcumin at 10, 20, 40 and $80 \mathrm{mg} / \mathrm{kg}$ (groups were named, $\mathrm{NC10}, \mathrm{NC20}, \mathrm{NC} 40$ and $\mathrm{NC} 80$ respectively); III) diabetic control group (DO): rats in this group received grape seed oil (O); IV) diabetic experimental groups: rats in these groups received curcumin at 10,20, 40 and $80 \mathrm{mg} / \mathrm{kg}$ 
(groups were named, DC10, DC20, DC40 and DC80 respectively) [10, 17-19]. Also we considered ethical principles for working with animals.

\subsection{Measured Parameters}

Blood glucose levels were measured in blood samples was taken from the lateral veins of the tail every three days on mornings at 9:00 am with a glucometer (One touch Profile, Life Scan). Serum insulin levels were measured three times, in the first day, middle and end of the experiment period, with the use of insulin kits (DRG, France), using double-antibody enzymelinked immunosorbent assay (ELISA). At the end of experiment period, they were sacrificed under light ether anesthesia. The abdomen was cut open and blood collected from heart. Serum was separated and the activity of alpha amylase was measured in serum.

\subsection{Statistical Analysis}

The data were analyzed with SPSS-22. Standard deviation was calculated in all cases and results expressed as mean \pm SD. The data were analyzed by one-sample Kolmogrov-Smirnov test and then by the Levene's test. One way analysis of variance (ANOVA) followed by Tukey's post hoc test for multiple comparisons were used to compare difference between experimental groups. The criterion for statistical significant was $\mathrm{P}<0.05$.

\section{Results}

With the technique of dialysis tube was showed that the attachment of curcumin to enzyme is reversible. Curcumin inhibited alpha amylase with an half maximal inhibitory concentration (IC50) value $51.32 \mu \mathrm{M}$. Graphical double reciprocal plots, Lineweaver-Burk plots showed that curcumin is a competitive inhibitor for alpha amylase (Figure 1). Dixon plot was subsequently drawn for curcumin and a Ki of $20.17 \mu \mathrm{M}$ was obtained for this compound (Figure 2). In animal's administration of STZ caused high levels (404.2 $\pm 35.2 \mathrm{mg} / \mathrm{dL}$ ) of blood glucose after 2 days in the treated groups in contrast with the normal control group $(107.8 \pm 9.6 \mathrm{mg} / \mathrm{dL})$. In two groups, DO and NO that received $0.5 \mathrm{~mL}$ daily grape seed oil, the blood glucose levels were nearly constant throughout the experimental period (Figure 3). But in experimental groups that received curcumin decreased blood glucose levels in diabetic and normal groups. In all groups and all doses that were used, this decrease was rapidly until about middle of the experimental period and was nearly constant until the end of the treatment. In diabetic and normal groups this effect appears to be dose-dependent manner, but there was no significant difference between the two doses of 40 and $80 \mathrm{mg} / \mathrm{kg}$. In diabetic and normal group's serum insulin levels were measured three times during the experiment are shown in Figure 4. Two days after STZ administration, serum insulin levels were significantly reduced in diabetic groups compared with normal groups. In diabetic and normal control groups, the serum insulin levels remained nearly constant throughout the experiment. But in diabetic and normal groups that received curcumin, serum insulin levels were significantly reduced. In diabetic and normal groups this decline in serum insulin level appears to be dose-dependent, while there was no significant difference between doses 40 and $80 \mathrm{mg} / \mathrm{kg}$. In diabetic and normal groups from day 15 of experiment, until the end of period, the serum insulin levels increased slightly (Figure $4)$.

In this study mentioned above, curcumin was found to inhibit HPA in vitro. In order to assess its effect in vivo, serum alpha amylase activities were also measured in diabetic and normal groups. In both diabetic and normal groups decreased levels of alpha amylase activity. In both diabetic and normal groups, this decrease was found to be significantly in $\mathrm{C} 20, \mathrm{C} 40$ and $\mathrm{C} 80$ doses in comparison with diabetic and normal control groups (DO and NO respectively) and C10. But the difference between the three mentioned doses was not significant (Table 1).

Table 1. The Effects of Different Doses of Curcumin on Alpha Amylase Activity in Diabetic and Normal Rats ${ }^{\mathrm{a}}$

\begin{tabular}{|c|c|}
\hline Groups & Amylase Activity, IU/L \\
\hline \multicolumn{2}{|c|}{ Diabetic Rats } \\
\hline DO & $1725.5 \pm 135.5$ \\
\hline DC10 & $1557.4 \pm 125.2$ \\
\hline DC20 & $1197.4 \pm 115.4^{\mathrm{b}, \mathrm{c}, \mathrm{d}}$ \\
\hline DC40 & $1159.2 \pm 105.5^{\mathrm{b}, \mathrm{c}, \mathrm{d}}$ \\
\hline DC80 & $1101.4 \pm 84.5^{\mathrm{b}, \mathrm{c}, \mathrm{d}}$ \\
\hline \multicolumn{2}{|c|}{ Normal Rats } \\
\hline No & $1652.4 \pm 128.5$ \\
\hline NC10 & $1526.2 \pm 123.5$ \\
\hline NC20 & $1211.2 \pm 112.5^{\mathrm{e}, \mathrm{f}, \mathrm{d}}$ \\
\hline NC40 & $1090.5 \pm 104.4^{\mathrm{e}, \mathrm{f}, \mathrm{d}}$ \\
\hline NC80 & $1075.4 \pm 89.5^{\mathrm{e}, \mathrm{f}, \mathrm{d}}$ \\
\hline \multicolumn{2}{|c|}{ 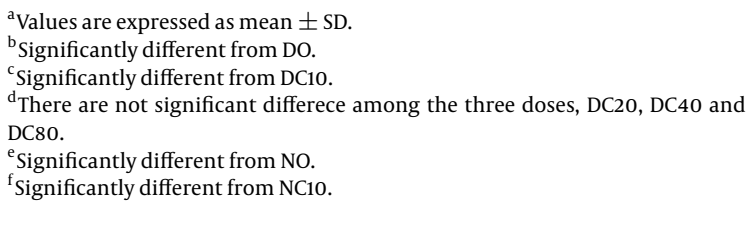 } \\
\hline
\end{tabular}




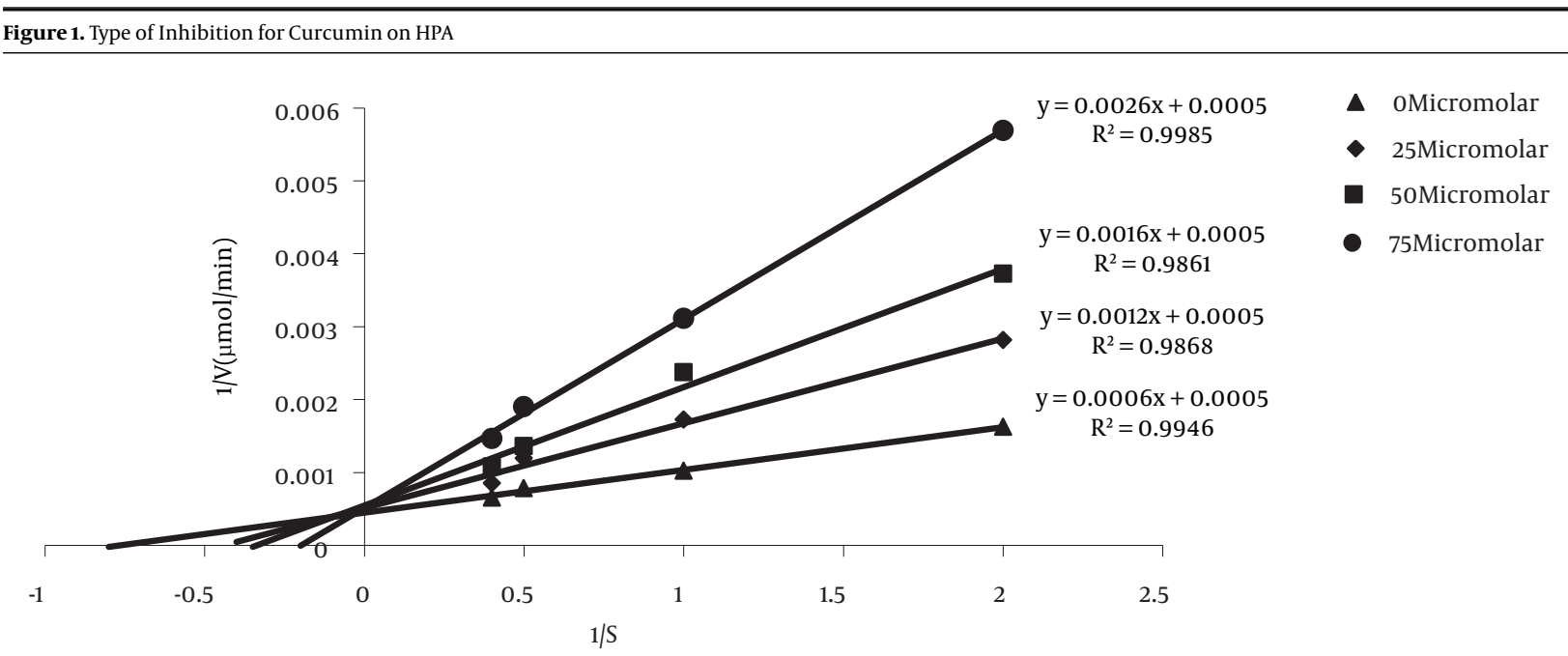

Linewear-Burk plot used to determine the type inhibition of curcumin toward HPA. Reverse values of activity $(1 / \mathrm{V})$ and substrate concentration $(1 / \mathrm{S}) \mathrm{w} / \mathrm{v}$ : $0.5 \%, 1.0 \%, 2.0 \%$ and $2.5 \%$ are plotted in absence of curcumin $(\mathbf{\bullet})$, and presence of three different concentrations of curcumin: $25 \mu \mathrm{M}(\bullet), 50 \mu \mathrm{M}(\boldsymbol{\bullet}), 75 \mu \mathrm{M}(\bullet)$.

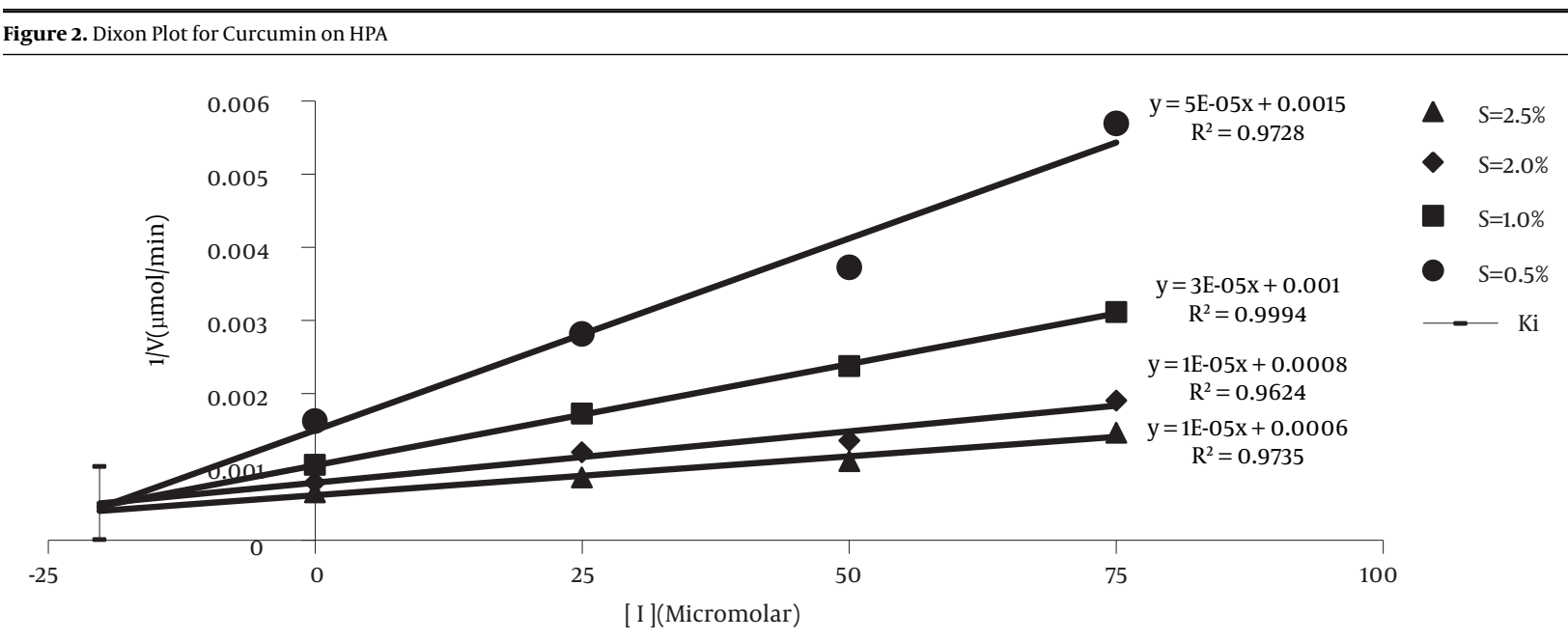

Dixon plot used to find the Ki of curcumin. Reverse values of activities $(1 / \mathrm{V})$ are plotted against $0,25,50$, and $75 \mu \mathrm{M}$ of curcumin [I], with the use of four different concentrations of the substrate expressed as w/v: $0.5 \%(\bullet), 1.0 \%(\boldsymbol{\bullet}), 2.0 \%(\bullet)$ and $2.5 \%(\mathbf{\Lambda})$.

\section{Discussion}

The result of this study showed that curcumin is a competitive inhibitor of alpha amylase and reduced level of blood glucose in diabetic and normal rats. Control of postprandial plasma glucose levels is important for the early treatment of diabetes complications. One of the therapeutic approaches to lower postprandial blood glucose is to inhibition breakdown of starch by inhibiting carbohydrate hydrolysis enzymes such as alpha amylase and alpha glucosidase. For this reason, efforts to develop new pharmacological agents focus on the inhibition these enzymes $[23,24]$. Alpha-amylase catalyzes the hydrolysis of $\alpha-(1$,
4)-D-glycosidic linkages of starch and other glucose polymers. Inhibitors of this enzyme could be of use in the treatment of diabetes. In diabetic patients, inhibition of alphaamylase leads to inhibition of starch breaking and results in lower levels of blood glucose [18]. Because of the harmful side-effects of synthetic products and the fact that plants are easily accessible, interest in drugs of herbal origin has significantly increased. From ancient times Curcuma longa (turmeric) was used as an antidiabetic drug. The main yellow bioactive component of turmeric is curcumin [25]. Curcumin is a tumeric-derived, water-insoluble polyphenol with potential beneficial health effects for humans 
A

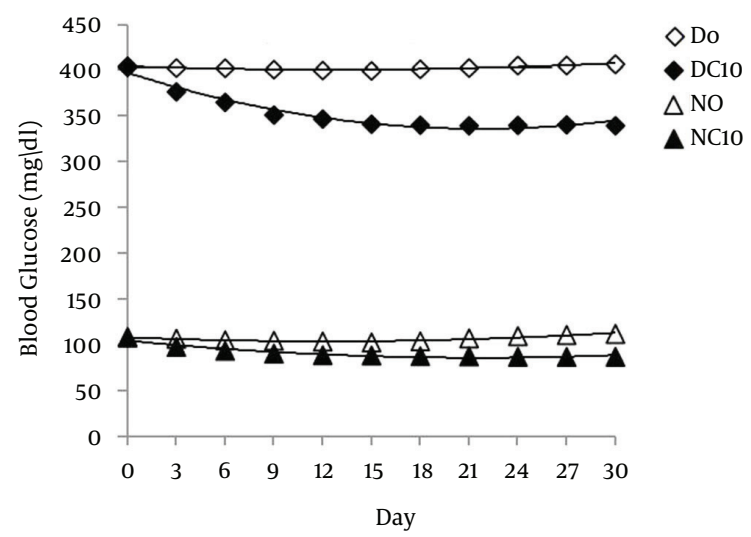

C

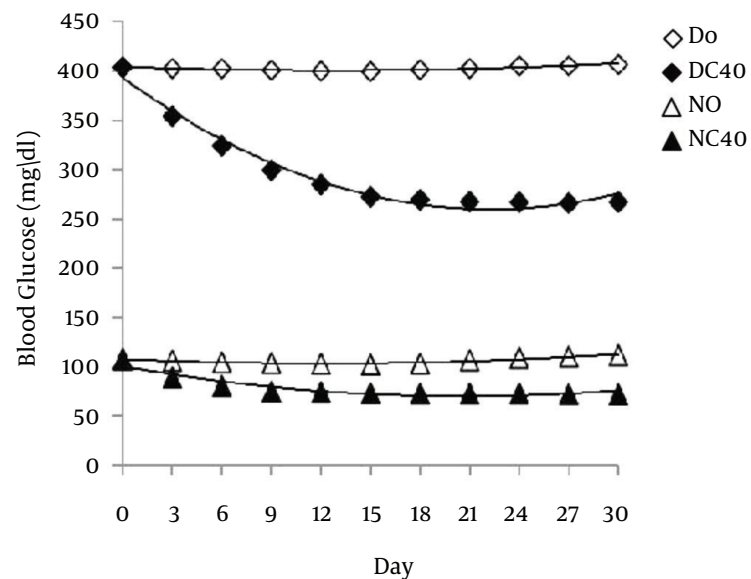

B

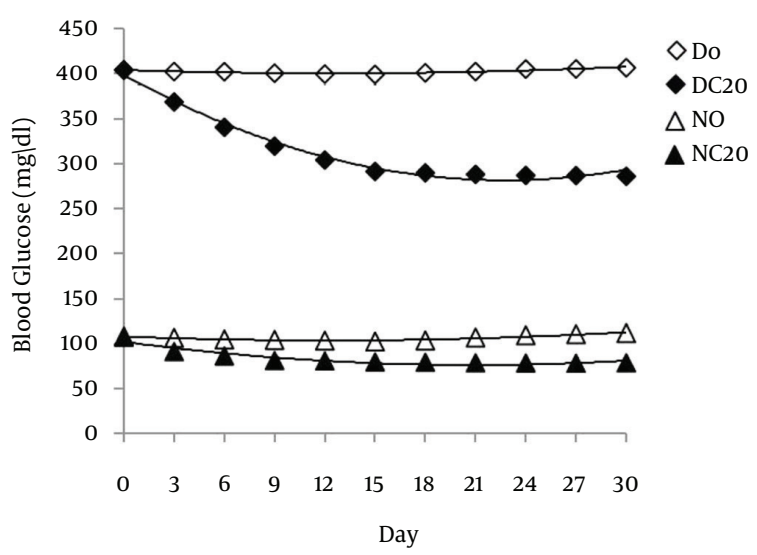

D

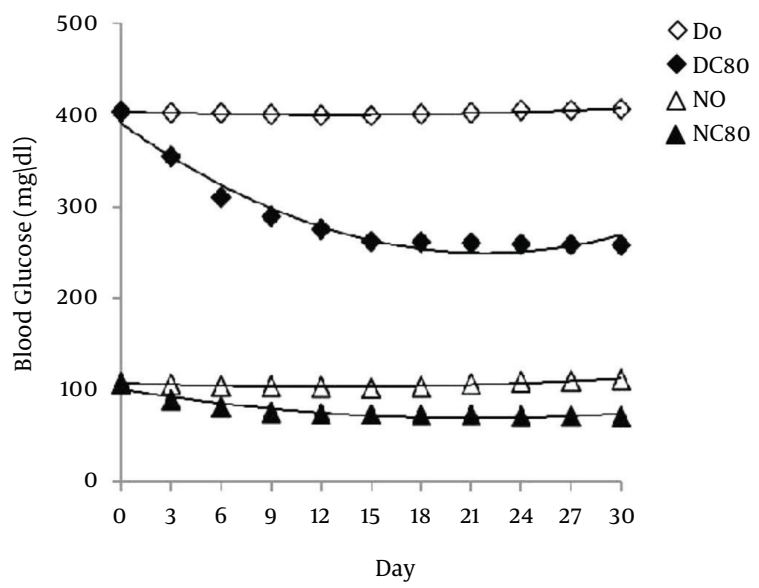

A, the effect of $10 \mathrm{mg} / \mathrm{kg}$ (B.W) of curcumin in diabetic (DC10) and normal groups (NC10); B, the effect of $20 \mathrm{mg} / \mathrm{kg}$ (B.W) of curcumin in diabetic (DC20) and normal groups (NC20); C, the effect of $40 \mathrm{mg} / \mathrm{kg}$ (B.W) of curcumin in diabetic (DC40) and normal groups (NC40); D, the effect of $80 \mathrm{mg} / \mathrm{kg}$ (B.W) of curcumin in diabetic (DC80) and normal groups (NC80).

[26]. Curcumin is rapidly metabolized and conjugated in the liver and excreted in the feces [11].

This study showed that curcumin with IC50 about 51.32 $\mu \mathrm{M}$ is a competitive inhibitor for alpha amylase. With drawing Dixon plot it was determined that Ki of curcumin on alpha amylase is $20.17 \mu \mathrm{M}$. Therefore curcumin is a nearly highly potent inhibitor for alpha amylase. Plants derived polyphenols such as quercetagetin, fisetin and quercetin which belong to the flavonoid family, have been shown to be effective inhibitors of mammalian alphaamylase with IC50s in the order of $\mu \mathrm{M}$ which is consistent with current research [20]. In Najafian et al. study trans chalcon inhibited alpha amylase. Trans chalcon is a polyphenolic compound such as curcumin which is con- sistent with current research [22].

In animals, administration of STZ caused high levels of blood glucose $[10,17,18,20]$. In diabetic and normal groups with administration curcumin, decreased blood glucose levels. Then may be the reduction of glucose level in diabetic and normal rats can be occurred via inhibition of alpha amylase by curcumin. It has been shown in previous researches that trans chalcon as a polyphenolic compound is a competitive inhibitor of alpha amylase which is consistent with current research [22]. In animals administration of STZ caused significantly reduced the level of insulin. In diabetic and normal groups with used curcumin decreased insulin serum levels. This decrease in insulin may be happen following reduced blood glucose levels or 

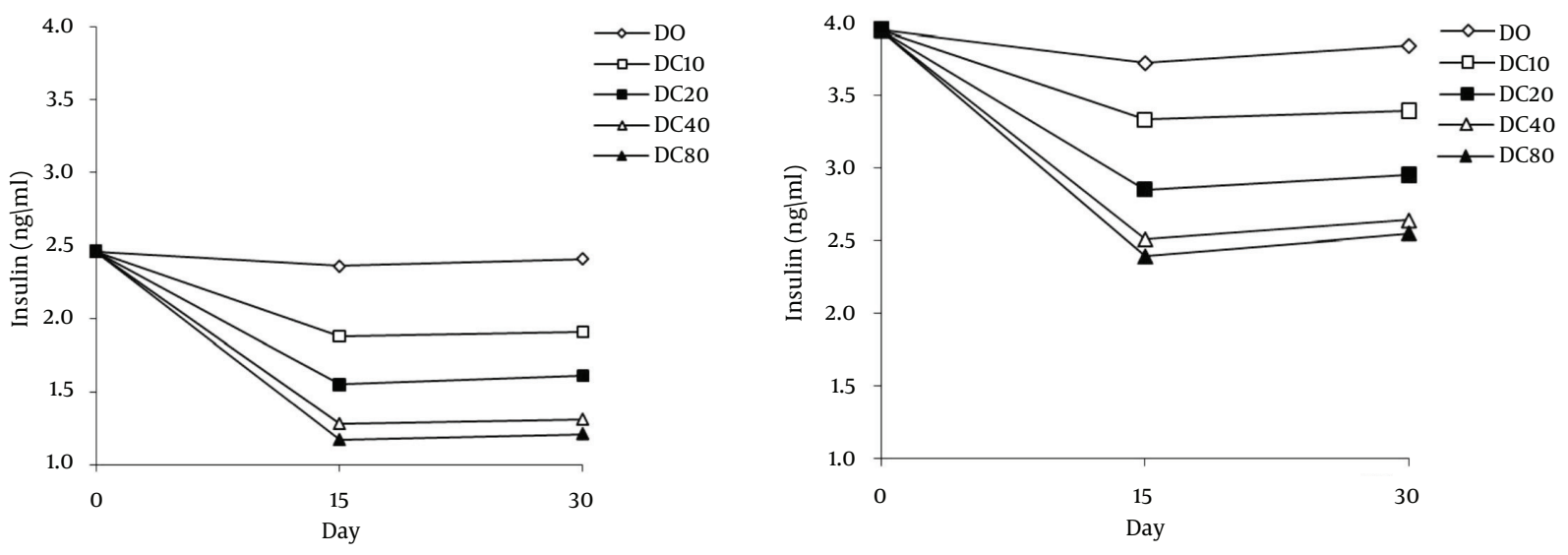

A, Diabetic Groups; B, Normal Groups.

may be this fact that curcumin improves insulin sensitivity and has imposing an anti-diabetic effect $[25,27]$.

In Najafian et al. study trans chalcon reduced insulin level in diabetic and normal rats which is consistent with current research [17]. The activity of alpha amylase in serum has decreased. This decrease may be such as in vitro experiment to be caused this fact that alpha amylase was inhibited by curcumin. As a result of the property antidiabetic effect of curcumin is in digestive system, and more via inhibition of degradation of polysaccharides. In abandon of in vitro study was shown that the curcumin is a competitive inhibitor for alpha amylase. Then may be the reduction of glucose level in diabetic and normal rats can be occurred via inhibition of alpha amylase by curcumin.

The best results were obtained in rats treated with 40 $\mathrm{mg} / \mathrm{kg}$ of curcumin. It may be concluded that curcumin has beneficial effects in the treatment of diabetes and related disorders. In addition this compound could be used to design effective inhibitors of alpha-amylase. It is necessary to examine the inhibitory effect of other polyphenolic compounds on alpha amylase and their effect on diabetic state.

\section{Acknowledgments}

The author is grateful to research deputy dean of the Islamic Azad university, Jahrom branch; Razy laboratory center of university of science and research of Tehran; laboratory of gland and metabolism center of Tehran university; and Shariaty hospital of Tehran. This research project with 51931911025001 code was done by Najafian.

\section{Footnotes}

Conflict of Interest: The author declares no conflict of interest.

Funding/Support: Islamic Azad university, Jahrom.

\section{References}

1. Kim JD, Kang SM, Seo BI, Choi HY, Choi HS, Ku SK. Anti-diabetic activity of SMK001, a poly herbal formula in streptozotocin induced diabetic rats: therapeutic study. Biol Pharm Bull. 2006;29(3):477-82. [PubMed: 16508149].

2. Guariguata L, Whiting D, Weil C, Unwin N. The International Diabetes Federation diabetes atlas methodology for estimating global and national prevalence of diabetes in adults. Diabetes Res Clin Pract. 2011;94(3):322-32. doi: 10.1016/j.diabres.2011.10.040. [PubMed: 22100977].

3. Shah H, Bodhankar S, Bhonde R, Mohan V. Combinative therapeutic approach for better blood sugar level control in alloxan diabetic mice. Int J Diabetes Metab. 2006;14(2):104.

4. Prasad SK, Kulshreshtha A, Qureshi TN. Antidiabetic activity of some herbal plants in streptozotocin induced diabetic albino rats. Pak J Nutr. 2009;8(5):551-7.

5. van Dieren S, Beulens JW, van der Schouw YT, Grobbee DE, Neal B. The global burden of diabetes and its complications: an emerging pandemic. Eur J Cardiovasc Prev Rehabil. 2010;17 Suppl 1:S3-8. doi: 10.1097/01.hjr.0000368191.86614.5a. [PubMed: 20489418].

6. Mahesh T, Sri Balasubashini MM, Menon VP. Photo-irradiated curcumin supplementation in streptozotocin-induced diabetic rats: effect on lipid peroxidation. Therapie. 2004;59(6):639-44. [PubMed: 15789828].

7. Kumar R, Arora V, Ram V, Bhandari A, Vyas P. Hypoglycemic and hypolipidemic effect of Allopolyherbal formulations in streptozotocin induced diabetes mellitus in rats. Int J Diabetes Mellitus. 2015;3(1):4550.

8. Patil A, Nirmal S, Pattan S, Tambe V, Tare M. Antidiabetic effect of polyherbal combinations in STZ induced diabetes involve inhibition of $\alpha$-amylase and $\alpha$-glucosidase with amelioration of lipid profile. Phytopharmacol. 2012;2(1):46-57. 
9. Saxena A, Vikram NK. Role of selected Indian plants in management of type 2 diabetes: a review. J Altern Complement Med. 2004;10(2):36978. doi: 10.1089/107555304323062365. [PubMed: 15165418].

10. Najafian M, Ebrahim-Habibi A, Yaghmaei P, Parivar K, Larijani B. Citral as a potential antihyperlipidemic medicine in diabetes: a study on streptozotocin-induced diabetic rats. J Diabetes and Metab Disord. 2011;10:3.

11. Padhye S, Chavan D, Pandey S, Deshpande J, Swamy KV, Sarkar FH. Perspectives on chemopreventive and therapeutic potential of curcumin analogs in medicinal chemistry. Mini Rev Med Chem. 2010;10(5):372-87. [PubMed: 20370702].

12. Yu WG, Xu G, Ren GJ, Xu X, Yuan HQ, Qi XL, et al. Preventive action of curcumin in experimental acute pancreatitis in mouse. Indian J Med Res. 2011;134(5):717-24. doi: 10.4103/0971-5916.91009. [PubMed: 22199113].

13. Hatcher H, Planalp R, Cho J, Torti FM, Torti SV.Curcumin: from ancient medicine to current clinical trials. Cell Mol Life Sci. 2008;65(11):1631-52. doi: 10.1007/s00018-008-7452-4. [PubMed: 18324353].

14. Chattopadhyay I, Biswas K, Bandyopadhyay U, Banerjee RK. Turmeric and curcumin: Biological actions and medicinal applications. Curr Sci Ind. 2004;87:44-53.

15. Ono K, Hasegawa K, Naiki H, Yamada M. Curcumin has potent antiamyloidogenic effects for Alzheimer's beta-amyloid fibrils in vitro. J Neurosci Res. 2004;75(6):742-50. doi: 10.1002/jnr.20025. [PubMed: 14994335].

16. Shehzad A, Lee YS. Curcumin: Multiple molecular targets mediate multiple pharmacological actions: A review. Drugs Fut. 2010;35(2):113. doi:10.1358/dof.2010.035.02.1426640.

17. Najafian M, Ebrahim-Habibi A, Yaghmaei P, Parivar K, Larijani B. Core structure of flavonoids precursor as an antihyperglycemic and antihyperlipidemic agent: an in vivo study in rats. Acta Biochim Pol. 2010;57(4):553-60. [PubMed: 21060897].

18. Najafian M, Jahromi MZ, Nowroznejhad MJ, Khajeaian P, Kargar MM, Sadeghi M, et al. Phloridzin reduces blood glucose levels and improves lipids metabolism in streptozotocin-induced diabetic rats. Mol biol rep. 2012;39(5):5299-306.

19. Najafian M. Effect of curcumin on metabolism of lipids in streptozotocin induced diabetic and normal rats. Biomed Pharm J. 2014;7(1):38391.

20. Mahmood N. A review of $\alpha$-amylase inhibitors on weight loss and glycemic control in pathological state such as obesity and diabetes. Comp Clin Pathol. 2014;InPress(InPress):1-12. doi: 10.1007/s00580-0141967-x.

21. Bernfeld P. Methods in Enzymology. Volume 1. Academic Press; 1955. pp. 149-51.[17] Amylases, $\alpha$ and $\beta$.

22. Najafian M, Ebrahim-Habibi A, Hezareh N, Yaghmaei P, Parivar K, Larijani B. Trans-chalcone: a novel small molecule inhibitor of mammalian alpha-amylase. Mol Biol Rep. 2011;38(3):1617-20. doi: 10.1007/s11033-010-0271-3. [PubMed: 20857221].

23. Sahin Basak S, Candan F. Chemical composition and In vitro antioxidant and antidiabetic activities of Eucalyptus Camaldulensis Dehnh. essential oil. Journal of the Iranian Chemical Society. ;7(1):216-26. doi: $10.1007 /$ bfo3245882.

24. Ponnusamy S, Ravindran R, Zinjarde S, Bhargava S, Ravi Kumar A. Evaluation of traditional Indian antidiabetic medicinal plants for human pancreatic amylase inhibitory effect in vitro. Evidence-Based Complementary Altern Med. 2010;1(1):1-10.

25. Mahfouz MKM. Curcumin improves insulin sensitivity and ameliorates serum proinflammatory cytokines levels in diabetes rat model irrespective of type of diabetes. J Am Sci. 2011;7(6):794-9.

26. Ung VY, Foshaug RR, MacFarlane SM, Churchill TA, Doyle JS, Sydora BC, et al. Oral administration of curcumin emulsified in carboxymethyl cellulose has a potent anti-inflammatory effect in the IL-10 genedeficient mouse model of IBD. Dig Dis Sci. 2010;55(5):1272-7. doi: 10.1007/s10620-009-0843-z. [PubMed: 19513843].
27. Na LX, Zhang YL, Li Y, Liu LY, Li R, Kong T, et al. Curcumin improves insulin resistance in skeletal muscle of rats. Nutr Metab Cardiovasc Dis. 2011;21(7):526-33. doi: 10.1016/j.numecd.2009.11.009. [PubMed: 20227862] 